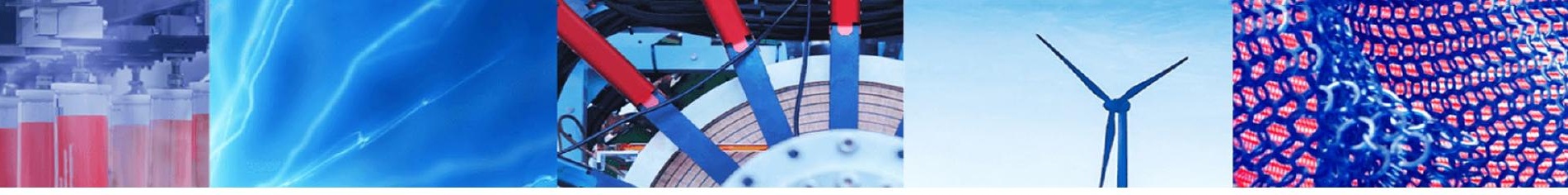

Research Article

\title{
Thermal properties of sand and mineral flours
}

\author{
Günter Buntebarth ${ }^{1}$ (D)
}

Received: 16 October 2019 / Accepted: 28 January 2020 / Published online: 13 February 2020

(C) The Author(s) $2020 \quad$ OPEN

\begin{abstract}
The determination of the thermal conductivity and the thermal diffusivity of granular dry material is exposed to the problem of heat transfer between the heat source of an instrument and the media of investigation. This problem can be solved by filling the pore space with various fluids. An empirical relation between the thermal conductivity and the diffusivity of the composed media and the thermal conductivity of the pore fluid is extrapolated to the value of air as a pore filling. A further method provides the heat contact conductance of the fluid-solid interface during a non-stationary state which allows the estimation of the thermal diffusivity for air in the pore space. The validity of the geometric mean, which is often used to estimate the thermal conductivity of composed media, is limited to a heat conductivity contrast of up to 1:20. The structural constant of Wiener's mixing rule represents not only a fixed structure of the pore space, but also relates to the heat transfer properties at the fluid-solid interface. It strongly varies with the surface tension of the fluid as well as with its wetting property.
\end{abstract}

Keywords Thermal conductivity · Thermal diffusivity · Mixing rules · Loose material · Porous media · Surface tension · Wetting property

\section{Introduction}

There are many experiments published about mixtures of sand and water as well as organic fluids. A comprehensive review is given by Somerton [16], reporting several usual and sophisticated mixing rules. Various rules of averaging are applied to natural sand/fluid mixtures which are reported by Askari et al. [1]. The main problem of the experiments is due to the variability of the pore structure, the grain size and shape as well as the ratio of the thermal properties of the constituents of the mixture [14] which limit their accuracy. These properties are often expressed with the formation factor which denotes an empirical parameter and which is determined with the electrical conductivity of a sample in relation to its porosity. It summarizes all structural effects with the so-called cementation factor [15] which describes the structure of the pore space in accordance with its electrical conductance. This method can, therefore, not be applied to dry samples. Berryman [3] introduced beside the formation factor of the pore space an additional formation factor of the solid framework which neither can solve the problem due to the interface thermal resistivity.

A further approach is reached for estimating thermal properties of composed media considering the structure of the matrix with the mixing rule of Wiener [21], which is based on the potential theory and introduces a structural constant. Buntebarth and Schopper [5] demonstrated the sensibility of this structural constant on the applied pore fluid with sedimentary rocks rich in quartz. The constant contains manifold information to the fluid-solid interface. Additional to the wetting property of the fluid, the structure of the surface can influence the wetting behavior, so that it can change from a hydrophilic to a hydrophobic behavior [7].

Günter Buntebarth, pggb@tu-clausthal.de | Institute of Geophysics, Technical University of Clausthal, 38678 Clausthal-Zellerfeld, Germany.

SN Applied Sciences (2020) 2:396 | https://doi.org/10.1007/s42452-020-2208-3 
Beside the internal structure of porous media, the interface between a flat or round measuring sensor and a sample plays a non-negligible role [18]. A theoretical approach [12] results the remarkable influence of the contact area on the interfacial thermal conductance. The determination of thermal properties of loose sediments and mineral flours is, therefore, exposed to the problem of the contact resistance between a plane heat source and the sample for measurement, because all contacts are only point contacts to the media (Fig. 1, section A- $A^{\prime}$ ) and, therefore, not representative for the whole sample (Fig. 1, section B-B'). $A$ cross section through the media to study the contact surface cannot be manufactured. In order to overcome the problem, the thermal conductivity of loose material is determined with different pore fluids. In order to minimize this apparent thermal contact resistance, suitable contact material can be added to solid samples. In this study, the thermal conductivity of loose material is determined by the addition of different pore fluids.

Several methods are applied to estimate the thermal conductivity as well as the thermal diffusivity of dry unconsolidated material $[10,16]$. With this study, empirical relations between both the properties and the thermal conductivity of the pore fluid are extrapolated to values for dry samples.

The geometric mean results in a fairly good effective thermal conductivity for composed media, but it yields wrong values with dry porous media. Its validity is tested with a variety of pore fluids.

Special attention is paid to the thermal contact conductance between the fluid and the solid. The effect of the difference between their thermal effusivity is investigated. The artificial mineral flours are crushed grains with surfaces containing physical defects, instead of rounded ones originated from weathering and transportation. Between the solid surface and the liquid phase, a thin layer occurs and Truong and Wayner [19] calculated specific properties of this thin film, which can reach a remarkable thickness for non-wetting fluids. Its thickness, called the Kapitza length, e.g., [2], contributes to the heat transfer with an additional thermal

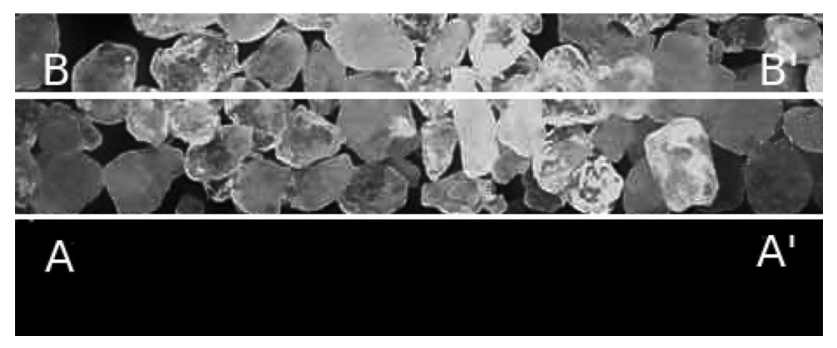

Fig. 1 Loose grains above a flat solid surface: a-a' boundary between both media. b-b' section through the granular medium resistance (Kapitza resistance), which also contributes to the structural constant as investigated in this study.

The cited investigations are mainly focused on the porosity dependence of the thermal conductivity of solid porous and loose granular media saturated with fluids. In this study, a constant porosity of mineral grains is considered with the pore space saturated with fluids of different thermal conductivities, in order to reveal the effective thermal conductivity of a dry matrix through extrapolating the effective thermal conductivity for a fluid-free pore space.

\section{Theory}

The bulk thermal properties of composed material are often estimated by applying various mixing rules. There are three usually used mathematical rules for weighted averaging, i.e., the arithmetic, harmonic and geometric mean. The first two rules are not representative for a complex pore space and can be understood as heat transfer through a parallel or perpendicular arrangement of matrix and pore space. On the other hand, the geometric mean agrees fairly well with water-saturated porous media, although it has no physical explanation. A more enhanced rule has been established by Wiener [21] on the basis of the potential theory [5]. This rule introduces a specific constant depending on the structure for a given sample. It relates the ratio of the effective thermal conductivity $K_{\text {tot }}$ to the matrix conductivity $K_{\text {mtx }}$ as a function of the ratio of the conductivity of the pore fluid $K_{\text {por }}$ to that of the matrix:

$\frac{K_{\mathrm{tot}}}{K_{\mathrm{mtx}}}=\frac{1-\xi \phi}{1+\alpha \xi \phi} \quad$ with $\quad \xi=\frac{1-K_{\mathrm{por}} / K_{\mathrm{mtx}}}{1+\alpha K_{\mathrm{por}} / K_{\mathrm{mtx}}}$

with $\phi$ as the porosity and $a$ as a structural constant of an unconsolidated material or solid porous media.

Small values of $a$, i.e., $a=0$ correspond to a structure with mainly parallel flow of heat through the matrix and pore space which equals the weighted arithmetic mean and large values, i.e., $a \rightarrow \infty$ corresponds to the weighted harmonic mean and indicates that the heat flow is dominated by addition of the thermal resistances [5].

Inserting the relation between the thermal diffusivity $\mathrm{K}$, the thermal conductivity $K$ as well as the density $\rho$ and the specific heat capacity c in Eqs. 1 and 2:

$\kappa=\frac{K}{\rho c}$

Equation (4) results:

$\frac{\kappa_{\mathrm{tot}}}{\kappa_{\mathrm{mtx}}}=\frac{1-\xi \phi}{(1+\alpha \xi \phi)(1+\phi(1-\delta))} \quad$ with $\quad \delta=\frac{\rho_{\mathrm{por}} c_{\mathrm{por}}}{\rho_{\mathrm{mtx}} c_{\mathrm{mtx}}}$ 
with the total thermal diffusivity $\kappa_{\text {tot }}$ the matrix thermal diffusivity $\kappa_{\mathrm{mtx}}$ the densities of the pore space $\rho_{\text {por }}$ and matrix $\rho_{\mathrm{mtx}}$ and their specific heat capacity $c_{\text {por }}$ and $c_{\mathrm{mtx}}$.

However, the thermal conductivity is determined during a stationary heat flow through the media, and the thermal diffusivity is determined during a non-steady process. The time dependence of the temperature at a fluid-solid interface can be described analytically [6] where the socalled heat penetration coefficient $S$ relates to the temperature change [17]. It is the ratio of the thermal effusivity of the pore fluid and that of the matrix:

$\frac{K_{\text {por }} \sqrt{\kappa_{\mathrm{mtx}}}}{\sqrt{\kappa_{\mathrm{por}}} K_{\mathrm{mtx}}}=\frac{\sqrt{K_{\text {por }} \rho_{\text {por }} C_{\text {por }}}}{\sqrt{K_{\mathrm{mtx}} \rho_{\mathrm{mtx}} C_{\mathrm{mtx}}}}=\mathrm{S}$

This coefficient is proportional to the temperature variation at a fluid-solid interface. It is therefore an important parameter during the determination of the total thermal diffusivity, which needs a non-steady state. However, it does not distinguish between a wetting or non-wetting pore fluid. The degree of wetting causes a varying thermal resistance at the fluid-solid interface which can be of significant importance, especially with non-wetting fluids [2]. This interfacial thermal resistance, called the Kapitza resistance, is part of the thermal heat transfer coefficient which defines the temperature drop at the interface between two materials.

\section{Methodology}

The thermal conductivity and thermal diffusivity have been simultaneously determined with the instrument, SolidTherm (www.geotec-instruments.com), which operates with a line source and an averaging platinum temperature sensor of length $40 \mathrm{~mm}$ and a diameter of $5 \mathrm{~mm}$. During the 2 min of measuring, the probe heats up (about $1-2 \mathrm{~K}$ ) and records the temperature reaction, which is affected by the surrounding sample material. In the following step, thermal conductivity and diffusivity are calculated based on the temperature graph according to the ASTM standard, D5334-08 and DIN EN ISO 22007-1:2012. The accuracy of the equipment is within $5 \%$ of the thermal conductivity and $10 \%$ of the thermal diffusivity.

Three granular samples were selected as matrix material, i.e., quartz sand, quartz flour and limestone flour. Their grain size is given in Table 1 and ranges from $<0.006 \mathrm{~mm}$ to $>0.4 \mathrm{~mm}$. The purity of quartz flour is $>98 \% \mathrm{SiO}_{2}$ (Quarzwerke $\mathrm{GmbH}$, Frechen/Germany) and that of limestone flour from Fischbach/Germany is $94 \%$ carbonate inclusive $2 \%$ dolomite (Rohrdorfer Zement, Geosystems Spezialbaustoffe GmbH Rohrdorf/Germany).

With experimental results of $K_{\text {tot }}$ and $\kappa_{\text {tot }}$ measured and $K_{\mathrm{mtx}}$ and $\kappa_{\mathrm{mtx}}$ assumed according to the literature [5, $9,16]$, the mixing rules and the structural constant $a$ can be determined applying Eqs. 1 and 2. A dense packing between face-centered and body-centered cubic of the dry particles is achieved to yield a porosity $\phi=36 \pm 1 \%$. The pressed particles fill a volume of $600 \mathrm{~cm}^{3}$, which is mixed with $220 \mathrm{ml}$ of different fluids, i.e., water, water with $25 \%$ $\mathrm{NaCl}$, glycerin, water with $38 \mathrm{wt} \%$ formic acid, water with $57 \mathrm{wt} \%$ ethanol, ethylene glycol, rapeseed oil, isopropanol or isooctane. The physical properties of the matrix are given in Table 2 and that of the liquids are in Table 3. They vary in surface tension, thermal conductivity, thermal diffusivity, specific heat capacity and wetting property. All of these parameters influence the heat transfer through the composed media.

\section{Results}

The thermal properties of mixtures of unconsolidated media with different fluids allow an estimation of the thermal properties of dry unconsolidated or porous media. Both the thermal conductivity and the thermal

Table 1 Grain size analysis (wt\%)

\begin{tabular}{llllllllr}
\hline Sieve mash size $(\mathrm{mm})$ & $>0.4$ & $0.4-0.315$ & $0.315-0.100$ & $0.100-0.063$ & $0.063-0.040$ & $0.040-0.020$ & $0.020-0.006$ & $<0.006$ \\
\hline Sand $(>95 \%$ Quartz) & 10.4 & 15.8 & 72.9 & 0.9 & & & \\
Quartz flour & 14 & & & 18 & 18 & 21 & 36 \\
Limestone flour & 16 & & & & & 27 \\
\hline
\end{tabular}

Table 2 Properties of the matrix $[5,9,16]$

\begin{tabular}{lllll}
\hline & $K_{\mathrm{mtx}}\left(\mathrm{W} \mathrm{m}^{-1} \mathrm{~K}^{-1}\right)$ & $\kappa_{\mathrm{mtx}}\left(\mathrm{mm}^{2} \mathrm{~s}^{-1}\right)$ & $\rho_{\mathrm{mtx}}\left(\mathrm{g} \mathrm{cm}^{-3}\right)$ & $c_{\mathrm{p} . \mathrm{mtx}}\left(\mathrm{J} \mathrm{g}^{-1} \mathrm{~K}^{-1}\right)$ \\
\hline Sand & 7.0 & 3.57 & 2.6 & 0.74 \\
Quartz flour & 7.0 & 3.57 & 2.6 & 0.74 \\
Limestone flour & 3.77 & 1.86 & 2.6 & 0.78 \\
\hline
\end{tabular}


Table 3 Surface tension $\sigma$ and thermal properties of the pore fluids $[8,11]$ as well as the difference between the experimentally determined thermal conductivity of saturated sand $K_{\text {tot }}$ and its geometric mean $K_{\text {geom. }}$ at various pore fillings

\begin{tabular}{|c|c|c|c|c|c|c|}
\hline Fluid & $\sigma\left(\mathrm{mN} \mathrm{m}^{-1}\right)$ & $\kappa_{\text {por }}\left(\mathrm{mm}^{2} \mathrm{~s}^{-1}\right)$ & $\begin{array}{l}K_{\text {pore }} \\
\left(\mathrm{W} \mathrm{m} \mathrm{m}^{-1} \mathrm{~K}^{-1}\right)\end{array}$ & $K_{\text {tot }}\left(\mathrm{W} \mathrm{m}^{-1} \mathrm{~K}^{-1}\right)$ & $\begin{array}{l}K_{\text {geom. }} \\
\left(\mathrm{W} \mathrm{m}^{-1} \mathrm{~K}^{-1}\right)\end{array}$ & $\begin{array}{l}\left(K_{\text {tot }}-K_{\text {geom }}\right) / K_{\text {tot }} \\
(\%)\end{array}$ \\
\hline Water & 72 & 0.14 & 0.60 & 3.12 & 2.96 & 5 \\
\hline Water with $25 \% \mathrm{NaCl}$ & 82 & 0.138 & 0.58 & 2.70 & 2.93 & -8 \\
\hline Water with 38 wt $\%$ formic acid & 51 & 0.135 & 0.49 & 2.78 & 2.76 & 1 \\
\hline Glycerin & 63 & 0.096 & 0.29 & 2.27 & 2.32 & -2 \\
\hline Water with 57 wt\% ethanol & 35 & 0.110 & 0.29 & 2.22 & 2.30 & -3 \\
\hline Ethylene glycol & 48 & 0.111 & 0.29 & 1.91 & 2.30 & -20 \\
\hline Rape oil & 30 & 0.088 & 0.14 & 1.56 & 1.78 & -14 \\
\hline Isopropanol & 22 & 0.068 & 0.14 & 1.30 & 1.77 & -59 \\
\hline Isooctane & 19 & 0.091 & 0.13 & 1.04 & 1.73 & -66 \\
\hline
\end{tabular}

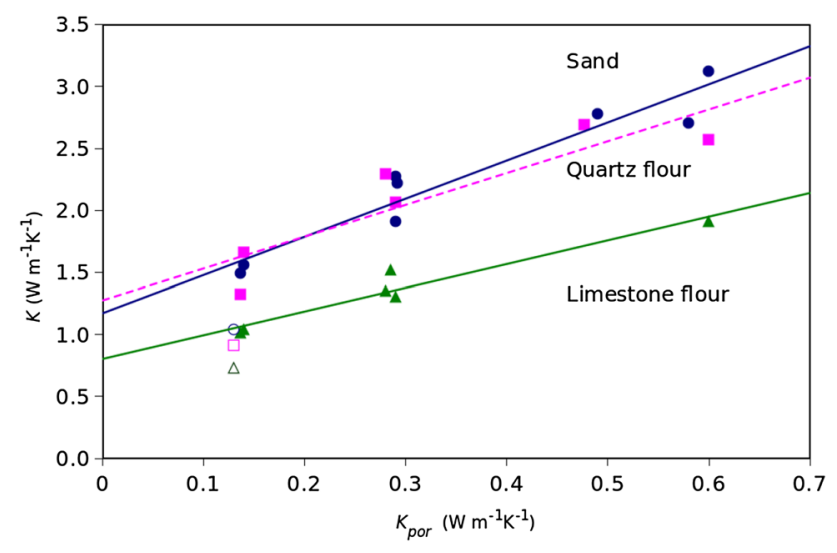

Fig. 2 The total thermal conductivity $K$ plotted against the thermal conductivity of the pore fluid $K_{\text {pori }}$ iopen marks denote the non-wetting isooctane fluid

diffusivity relate to the thermal conductivity of the pore fluid, which enables the estimation of the properties of gas-filled porous media. The application of the geometric mean is limited and cannot be applied to dry porous media. Wiener's mixing rule provides deeper insights to the fluid-solid interface.

\subsection{Relation between bulk thermal properties and the thermal conductivity of pore fluid}

The bulk thermal conductivity and the thermal diffusivity of granular media are displayed with respect to the thermal conductivity of the pore fluid in Figs. 2 and 3. A linear relation can be assumed between the total conductivity and that of the pore fluid. The total thermal diffusivity is also dominated by the thermal conductivity of the pore fluid and results in a linear relationship (Table 4).

Both empirical relations can be applied to estimate the thermal properties for gas-filled porous materials (Table 5).

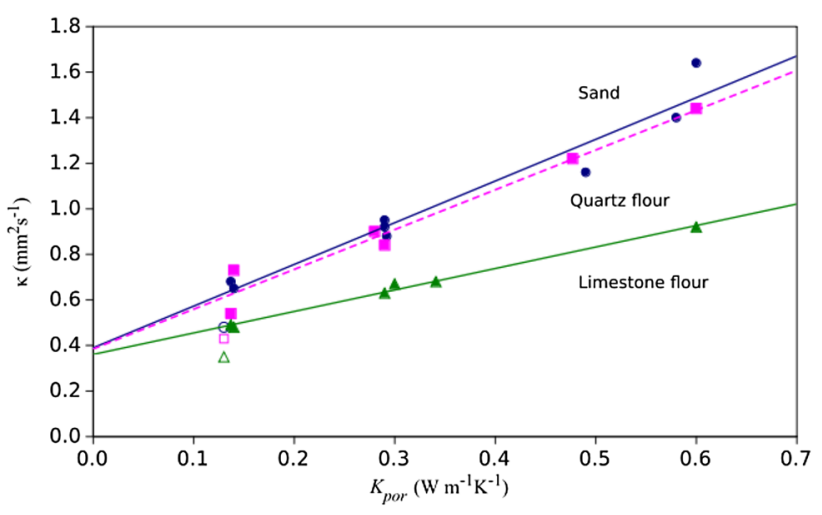

Fig. 3 The total thermal diffusivity $k$ plotted against the thermal conductivity of the pore filling $K_{\text {pori }}$ open marks denote the nonwetting isooctane fluid

As demonstrated in Figs. 2 and 3, the non-wetting isooctane results indicate a lower conductivity than expected. Therefore, it is not included in the trend. The thermal conductivity is reduced by ca. $30-40 \%$ compared to the trend of the wetting fluids and the thermal diffusivity is reduced by $20-30 \%$ (Table 6 ).

\subsection{The geometric mean of thermal properties of matrix and pore fluid}

The trend of the measured mixtures can satisfactorily be described with a logarithmic function within the range of the conductivity of the applied wetting pore fluids. It is equivalent to the geometric mean.

$\ln \left(K_{\text {tot }}\right)=c_{1} \ln \left(K_{\text {por }}^{a}\right)+c_{2}$

The constants $c_{1,2}$ and the apparent conductivity $K_{\text {por }}^{a}$ are determined with the trend and agree within an error bar of $10 \%$ over a limited range (Table 3 ). This case study 
Table 4 The trend of the total thermal conductivity and thermal diffusivity with the regression coefficient according to Figs. 2, 3 and 5

Table 5 Estimated thermal properties with air $\left(K=0.026 \mathrm{~W} \mathrm{~m}^{-1} \mathrm{~K}^{-1}\right)$ filled porous media at the apparent density $\rho$ according to Figs. 2 , 3 and Eq. 6

\begin{tabular}{llllllllll}
\hline & \multicolumn{3}{l}{ Sand $a_{\mathrm{s}} b_{\mathrm{s}} R^{2}$} & \multicolumn{4}{c}{ Quartz flour $a_{\mathrm{q}} b_{\mathrm{q}} R^{2}$} & \multicolumn{3}{c}{ Limestone flour $a_{1} b_{1} R^{2}$} \\
\hline$K_{\text {tot }}=\mathrm{a} K_{\mathrm{p}}+\mathrm{b}$ & 3.092 & 1.163 & 0.93 & 2.669 & 1.206 & 0.86 & 1.900 & 0.782 & 0.93 \\
$K_{\text {tot }}=\mathrm{a} K_{\mathrm{p}}+\mathrm{b}$ & 1.836 & 0.386 & 0.95 & 1.788 & 0.341 & 0.95 & 0.943 & 0.361 & 0.99 \\
$\ln \left(\kappa_{\text {tot }}\right)=\mathrm{a} S+\mathrm{b}$ & 2.757 & 0.782 & 0.97 & 2.926 & 0.908 & 0.88 & 1.674 & 1.014 & 0.99 \\
\hline
\end{tabular}

\begin{tabular}{llll}
\hline Thermal property & $\begin{array}{l}\text { Sand } \\
\rho=1.68 \mathrm{~g} \mathrm{~cm}^{-3}\end{array}$ & $\begin{array}{l}\text { Quartz flour } \\
\rho=1.54 \mathrm{~g} \mathrm{~cm}^{-3}\end{array}$ & $\begin{array}{l}\text { Limestone flour } \\
\rho=1.47 \mathrm{~g} \mathrm{~cm}^{-3}\end{array}$ \\
\hline Thermal conductivity $\left(\mathrm{W} \mathrm{m}^{-1} \mathrm{~K}^{-1}\right)$, Fig. 2 & 1.24 & 1.28 & 0.83 \\
Thermal diffusivity $\left(\mathrm{mm}^{2} \mathrm{~s}^{-1}\right)$, Fig. 3 & 0.41 & 0.39 & 0.39 \\
Thermal diffusivity $\left(\mathrm{mm}^{2} \mathrm{~s}^{-1}\right)$, Eq. 7 & 0.45 & 0.41 & 0.36 \\
\hline
\end{tabular}

Table 6 Difference of thermal properties between the trend of wetting fluids and the non-wetting isooctane as pore fluid

\begin{tabular}{|c|c|c|c|c|c|c|}
\hline \multirow[t]{2}{*}{ Fluid } & \multicolumn{2}{|c|}{ Sand $\rho=1.68 \mathrm{~g} \mathrm{~cm}^{-3}$} & \multicolumn{2}{|c|}{ Quartz flour $\rho=1.54 \mathrm{~g} \mathrm{~cm}^{-3}$} & \multicolumn{2}{|c|}{ Limestone flour $\rho=1.47 \mathrm{~g} \mathrm{~cm}^{-3}$} \\
\hline & $K\left(\mathrm{~W} \mathrm{~m}^{-1} \mathrm{~K}^{-1}\right)$ & $\kappa\left(\mathrm{mm}^{2} \mathrm{~s}^{-1}\right)$ & $K\left(\mathrm{~W} \mathrm{~m}^{-1} \mathrm{~K}^{-1}\right)$ & $\kappa\left(\mathrm{mm}^{2} \mathrm{~s}^{-1}\right)$ & $K\left(\mathrm{~W} \mathrm{~m}^{-1} \mathrm{~K}^{-1}\right)$ & $\kappa\left(\mathrm{mm}^{2} \mathrm{~s}^{-1}\right)$ \\
\hline Wetting (expected) & 1.56 & 0.62 & 1.55 & 0.57 & 1.03 & 0.48 \\
\hline Non-wetting & 1.04 & 0.48 & 0.91 & 0.43 & 0.73 & 0.35 \\
\hline Difference (\%) & -33 & -20 & -41 & -25 & -29 & -27 \\
\hline
\end{tabular}

\subsection{Effect of the thermal effusivity}

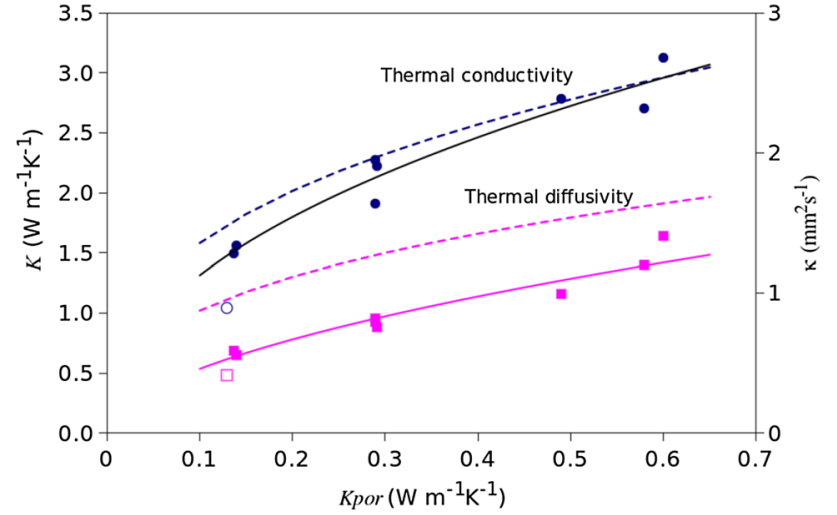

Fig. 4 Thermal conductivity $K$ and thermal diffusivity $K$ of sand with respect to the thermal conductivity of the pore fluid $K_{\text {pori }}$ the solid line represents an exponential relation and the dashed line the geometric mean; open symbols denote the non-wetting isooctane fluid, which is not considered in the trend

of sand allows a ratio of ca. 20:1 between the heat conductivity of the matrix and that of the pore fluid, which excludes gas-filled pores. Figure 4 shows that the thermal diffusivity cannot be estimated with the geometric mean because the different density and specific heat capacity of the matrix and the pore fluid are not taken into account.
The heat transfer in porous media is dominated not only by the heat conductivity of the pore fluid. The density $\rho$ and the specific heat capacity $c_{p}$, which are usually different from that of the matrix, relate also to the heat transfer at the fluid-solid interface. The heat penetration coefficient $S$, which is defined in Eq. 6 as the ratio of the thermal effusivity of the pore fluid and that of the matrix, controls the temperature transition between the pore space and the matrix during a non-steady state, i.e., during the determination of the thermal diffusivity. The relation between both parameters is shown in Fig. 5. An exponential relation shows the trend as the best fit to the measured data (Table 4).

The thermal effusivity of air is $5.8 \mathrm{~W} \mathrm{~s}^{1 / 2} \mathrm{~m}^{-2} \mathrm{~K}^{-1}$, if the thermal conductivity of $0.026 \mathrm{~W} \mathrm{~m}^{-1} \mathrm{~K}^{-1}$ and the thermal diffusivity of $20 \mathrm{~mm}^{2} \mathrm{~s}^{-1}$ [9] are applied. The heat penetration coefficient of quartz grains with air in the pore space is 0.0016 and that of limestone is 0.0021 , so that the thermal diffusivity can be estimated for the air-filled media. The extrapolated thermal diffusivity of dry sand and mineral flours is calculated in Table 5 . The results of these materials are determined at the given density only.

The thermal diffusivity of the non-wetting isooctane is not included in the trend. A systematic deviation from the trend is determined (Table 7) and indicates an additional transient thermal resistance. This difference is 


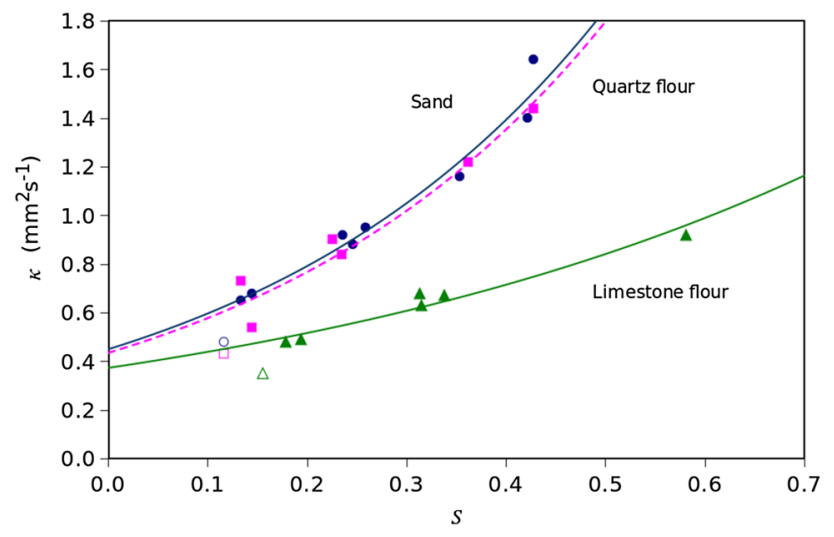

Fig. 5 The total thermal diffusivity $\kappa$ with respect to the heat penetration coefficient $S$; the exponential trend is the best fit to the measured data; open marks denote the non-wetting isooctane, ignored in the trend

a measure of the additional thermal resistance at the fluid-solid interface and the Kapitza resistance [2].

\subsection{Structural properties of the mixtures}

The structural constant $a$, which is defined in Eqs. 1 and 2 , indicates that the thermal properties of porous rocks are strongly dependent on the pore fluid [5]. If wetting properties change the apparent specific inner surface, the structural constant also changes. Such changes are attributed to the contribution of micro-cracks at different scales [5]. In this study, loose grains are without cracks of various scales. Nevertheless, the surface tension of the applied fluids causes a remarkable variation of the structural constant. During imbibition of a porous media, the matrix expands, which leads to an increase in the volume of the grains (e.g., $[4,20])$ and this increase relates linearly to the surface tension of the pore fluid [13]. As a result, the higher the surface tension of the pore fluid, the higher the increase in the matrix volume according to its apparent linear relation [13]. As a consequence, the specific inner surface decreases, diminishing the structural constant so that the structural constant is inversely related to the surface tension of the pore fluid. Figure 6 supports this assumption. The linear relation between the structural constant and the reciprocal surface tension with its regression

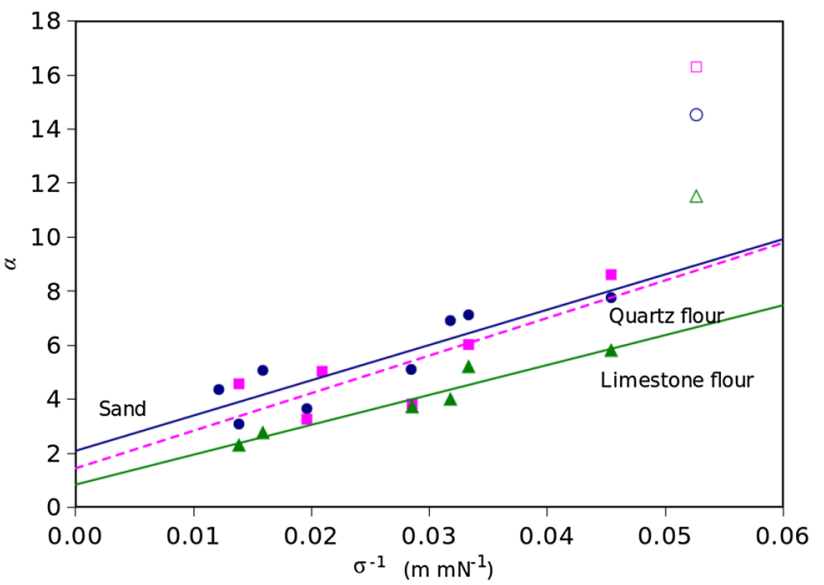

Fig. 6 The structural constant $a$ with respect to the reciprocal surface tension of the pore fluid; open marks denote the non-wetting isooctane fluid

Table 8 The trend of the structural constant $a$ with respect to surface tension $\sigma$ with the regression coefficient according to Fig. 6

\begin{tabular}{lcc}
\hline & Structural constant $a$ & $R^{2}$ \\
\hline Sand & $130.6 \sigma^{-1}+2.09$ & 0.79 \\
Quartz flour & $138.5 \sigma^{-1}+1.46$ & 0.67 \\
Limestone flour & $110.7 \sigma^{-1}+0.84$ & 0.92 \\
\hline
\end{tabular}

coefficient is given in Table 8. Remarkable differences occur between the structural constant of the pore filling with the non-wetting isooctane and the expected value of a wetting fluid with the same surface tension (Table 9).

\section{Discussion}

The thermal conductivity and thermal diffusivity of granular media are investigated with special attention to the effect of different pore fillings. The relations between measurements and other physical properties show that not only the individual properties of the components determine the effective thermal behavior but also the relation between each component.
Table 7 The difference between the thermal effusivity $K_{\text {tot }} / \sqrt{ } \kappa_{\text {tot }}$ of the non-wetting fluid isooctane and the trend of wetting fluids

\begin{tabular}{llll}
\hline Fluid & $\begin{array}{l}\text { Sand } \\
K_{\text {tot }} / \sqrt{ } \kappa_{\text {tot }} \\
\left(10^{3} \mathrm{~W} \mathrm{~s}^{1 / 2} \mathrm{~m}^{-2} \mathrm{~K}^{-1}\right)\end{array}$ & $\begin{array}{l}\text { Quartz flour } \\
K_{\text {tot }} / \sqrt{ } \kappa_{\text {tot }} \\
\left(10^{3} \mathrm{~W} \mathrm{~s}^{1 / 2} \mathrm{~m}^{-2} \mathrm{~K}^{-1}\right)\end{array}$ & $\begin{array}{l}\text { Limestone flour } \\
K_{\text {tot }} / \sqrt{ } \kappa_{\text {tot }}\left(10^{3} \mathrm{~W} \mathrm{~s}^{1 / 2} \mathrm{~m}^{-2} \mathrm{~K}^{-1}\right)\end{array}$ \\
\hline Wetting (expected) & 1.98 & 2.05 & 1.49 \\
Non-wetting & 1.50 & 1.39 & 1.23 \\
Decrease (\%) & 24 & 32 & 17 \\
\hline
\end{tabular}


Table 9 The difference between the structural constant $a$ of the pore filling with the non-wetting isooctane and the trend with wetting fluids

\begin{tabular}{llll}
\hline & \multicolumn{2}{l}{ Structural constant a } \\
\cline { 2 - 4 } & Sand & Quartz flour & Limestone flour \\
\hline Result of experiment & 17.3 & 16.3 & 11.0 \\
Expected from trend & 9.0 & 9.2 & 6.7 \\
Difference (\%) & 92 & 77 & 64 \\
\hline
\end{tabular}

\subsection{Relation between bulk thermal properties and thermal conductivity of the pore fluid}

If the linear relations (Table 4) are applied to estimate the effective thermal properties of a dry matrix, a more realistic value can be achieved than with measurement of the dry sample, because the above-mentioned interface problem between the measuring probe and sample is avoided. The results reported by Sommerton ([16], p. 72) show also a linear relationship between the thermal conductivities of the matrix and the applied fluids, except for the dry sample, whose effective thermal conductivity is too low to fit the linear trend. This misfit leads to the reported nonlinear trend, which is independent of the measuring method (e.g., [18]).

A further effect interferes the linear relationship with the wetting behavior of the pore fluid.

Figures 2 and 3 demonstrate that the non-wetting pore fluid isooctane does not fit the linear relation. The reduced thermal properties mean that an additional thermal resistance exists between the solid matrix and the pore fluid. This transition zone of some thickness, known as the Kapitza length [2], has a non-negligible influence on the heat transport. The thermal conductivity as well as the thermal diffusivity is ca. $30-40 \%$ and $20-30 \%$ below the value which would be expected for a wetting fluid, respectively (Table 6). The difference between both thermal properties can be understood by the contribution of a gas film with its high thermal diffusivity but low thermal conductivity. This film results from the hydrophobic behavior of the non-wetting fluid.

\subsection{The geometric mean of thermal properties of matrix and pore fluid}

The estimation of the total thermal properties using the geometric mean, which yields fairly good results with water-saturated rocks, demonstrates that the deviation from the experiment increases with the difference between the thermal conductivity of the matrix and that of the pore fluid, which has been already discussed (e.g., $[5,8])$. Sand as matrix shows that the geometric mean can be applied to mixtures with a heat conductivity ratio of up to 1:20. Therefore, its application to dry samples results in inaccurate values. It demonstrates, however, that the bulk thermal conductivity of crystalline rocks with several components of similar thermal conductivity can be averaged using the geometric mean.

\subsection{Effect of the thermal effusivity}

The exponential function between the thermal diffusivity and the heat penetration coefficient (Table 4) allows for estimation of the total thermal diffusivity of loose materials with air in the pore space; however, it cannot be extrapolated for higher values of the heat penetration coefficient $S$, which reaches $S=1$ for a pure matrix, because the exponential function is not ascertained for $S>0.6$. The results of the loose materials are valid at the given density only when representing densely packed spheres with a porosity of ca. $36 \%$.

The thermal effusivity of isooctane as pore fluid should be higher than the measurements demonstrate (Table 7). The reason is the additional thermal resistance at the solid-liquid interface which is created by its non-wetting behavior and which reduces the apparent thermal effusivity by ca. 20-30\%. Its effect is somewhat lower for the thermal diffusivity than for the thermal conductivity, as Table 6 indicates. The gas phase at the fluid-solid interface has a relatively high thermal diffusivity and explains the resulting difference.

\subsection{Structural properties of the mixtures}

Considering the trend of the relation between the structural constant and the surface tension, the regression coefficient ranges from $R^{2}=0.67-0.92$. The main reason of the scatter might be that the thermal contact conductance is also sensitive to the wetting behavior. Figure 6 shows that the non-wetting isooctane fluid causes a remarkable increase in the structural constant a which reaches $64-92 \%$ compared to the trend of wetting fluids at a surface tension of $19 \mathrm{mN} \mathrm{m}^{-1}$ (Table 9). This sensitivity of the structural constant to the wetting property likely causes the scatter at Fig. 6 and the low regression coefficient. The scatter of the wetting fluids might be due to their molecular character in combination with that of the matrix. The strong rise of the structural constant a with isooctane as pore fluid means that the significance of serial heat resistances raises in relation to that of parallel resistances. It is understood as the Kapitza resistance, which surrounds the matrix grains and reduces the heat flow. A temperature drop between the solid and the liquid phase occurs, and therefore, the total thermal conductivity is lowered. The total thermal diffusivity does not decrease as much. It points out that 
the volumetric heat capacity of the fluid-solid interface decreases much less.

The mean diameter of the sand particles is ca. $0.2 \mathrm{~mm}$ and that of the quartz flour is only $0.04 \mathrm{~mm}$. While the specific inner surface of both media is very different, the structural constant is similar. This appearance can be understood, if the surface structure of the grains is taken into account. Since the sand grains are rounded, the quartz flour particles have physical defects with peaks and sharp edges that impede the wetting by the fluid molecules [7]. Therefore, the physical specific inner surface is not identical with the apparent specific inner surface.

\section{Conclusion}

The determination of the heat conductivity and the thermal diffusivity of non-consolidated dry mineral grains is exposed to the heat contact conductance between the heat source of the instrument and the granular media. In order to avoid the effect of this thermal resistance between dry granular media and the heat source of the equipment, the loose grains are saturated with different fluids. The extrapolation of the measured thermal properties of the fluid/solid mixture for dry material results the properties for gas-filled pores. A linear relation can be applied between the total thermal conductivity and the thermal diffusivity and that of the pore fluid. The thermal diffusivity of dry mixtures can also be estimated with the thermal effusivity of fluid/solid mixtures. It turned out that a non-wetting fluid departs from the relationships, because an additional thermal resistance surrounds the grains, causes a temperature drop and reduces the heat flow.

Beside the empirical relations, two rules of averaging are applied. The geometric mean of the thermal conductivity of fluid and matrix properties, which is often applied, results in fairly good results in a limited range of the ratio of the properties between matrix and fluid. Dry granular media, however, are excluded. A further mixing rule, which includes a structural parameter, provides more details to the sensibility of the wetting behavior of the applied fluids and demonstrates a dependence on the surface tension.

Acknowledgements Open Access funding provided by Projekt DEAL. The author would like to thank Dr. W. Debschütz from the Institute of Geophysics of the Technical University of Clausthal for many discussions during the measurements, Ryan Wigg from the Institute of Applied Geology of the Georg-August-University of Göttingen for linguistic improvement and the company Rohrdorfer Zement, Geosystems Spezialbaustoffe $\mathrm{GmbH}$ for providing the mineral flours with analysis. I thank the two anonymous reviewers for very constructive comments.

\section{Compliance with ethical standards}

Conflict of interest The author declares that there is no conflict of interest.

Open Access This article is licensed under a Creative Commons Attribution 4.0 International License, which permits use, sharing, adaptation, distribution and reproduction in any medium or format, as long as you give appropriate credit to the original author(s) and the source, provide a link to the Creative Commons licence, and indicate if changes were made. The images or other third party material in this article are included in the article's Creative Commons licence, unless indicated otherwise in a credit line to the material. If material is not included in the article's Creative Commons licence and your intended use is not permitted by statutory regulation or exceeds the permitted use, you will need to obtain permission directly from the copyright holder. To view a copy of this licence, visit http://creativecommons. org/licenses/by/4.0/.

\section{References}

1. Askari R, Taheri S, Hejazi SH (2015) Thermal conductivity of granular porous media: a pore scale modeling approach. AIP Adv 5:097106. https://doi.org/10.1063/1.4930258

2. Barrat J-L, Chiaruttini F (2003) Kapitza resistance at the solidliquid interface. Mol Phys. https://doi.org/10.1080/0026897031 000068578

3. Berryman JG (2005) Thermal conductivity of porous media. Appl Phys Lett 86:032905. https://doi.org/10.1063/1.1852718

4. Buntebarth G (2002) Volumenvergrößerung von Sedimentgesteinen bei Wassersättigung. Mitt Dtsche Geophys Ges III: 41-44 ISSN-Nr. 0947-1944

5. Buntebarth G, Schopper JR (1998) Experimental and theoretical investigations on the influence of fluids, solids and interactions between them on thermal properties of porous rocks. Phys Chem Earth 23:1141-1146

6. Carslaw HS, Jaeger JC (1959) Conduction of heat in solids. Clarendon Press, Oxford, pp 2.50-2.91

7. De Gennes P-G, Brochard-Wyart F, Quéré $D$ (2004) Capillarity and wetting phenomena-drops, bubbles, pearls, waves. Springer, New York

8. Hemminger W (1989) Wärmeleitfähigkeit. In: Blanke W (ed) Thermophysikalische Stoffgrößen, Wärme- und Stoffübertragung. Springer, Berlin, pp 5.215-5.229

9. Kapplemeyer O, Haenel R (1974) Geothermics - with special reference to application. Borntraeger, Berlin, pp 6.211-6.221

10. Kaviany M (1991) Principles of heat transfer in porous media. Springer, New York, pp 3.115-3.148

11. Kirchner H-H, Dammann W, Hanitzsch E, Meerländer G, Klingenberg G (1989) Thermodynamische und mechanische Eigenschaften von Flüssigkeiten. In: Blanke W (ed) Thermophysikalische Stoffgrößen, Wärme- und Stoffübertragung. Springer, Berlin, pp 3.103-3.156

12. Liu C, Wei Z, Wang J, Bi K, Yang J, Chen J (2015) The contact area dependent interfacial thermal conductance. AIP Adv 5:127111. https://doi.org/10.1063/1.4937775

13. Möller M, Buntebarth G, Weller A (2018) Expansion and shrinkage of sandstones during spontaneous imbibition of fluids. Environ Earth Sci. https://doi.org/10.1007/s12665-018-7753-3 
14. Nan C-W, Birringer R, Clarke DR, Gleiter H (1997) Effective thermal conductivity of particulate composites with interfacial thermal resistance. J Appl Phys 81:6692. https://doi. org/10.1063/1.365209

15. Revil A (2000) Thermal conductivity of unconsolidated sediments with geophysical applications. J Geophys Res 105(B7):16749-16768

16. Somerton WH (1992) Thermal properties and temperaturerelated behavior of rock/fluid systems. Elsevier, Amsterdam

17. Tautz $\mathrm{H}$ (1971) Wärmeleitung und Temperaturausgleich. Akademie-Verlag, Berlin, pp 12.275-12.304

18. Tokura I (1990) Applicability of the hot-wire method to thermal conductivity measurement of two- phase mixtures. In: Cremers CJ, Fine HA (eds) Thermal conductivity 21. Plenum Press, New York, pp 165-176

19. Truong JG, Wayner PC (1987) Effect of capillary and van der Waals dispersiv forces on the equilibrium profile of a wetting liquid: theory and experiment. J Chem Phys 87:4180-4188
20. Weiss T, Siegesmund S, Kirchner D, Sippel J (2004) Insolation weathering and hygric dilatation: two competitive factors in stone degradation. Environ Geol. https://doi.org/10.1007/s0025 4-004-1041-0

21. Wiener O (1912) Die Theorie des Mischkörpers für das Feld der stationären Strömung. Abhandl Math-phys KI Königl Sächs Ges Wiss 32:507-604

Publisher's Note Springer Nature remains neutral with regard to jurisdictional claims in published maps and institutional affiliations. 